Check for updates

Cite this: RSC Adv., 2019, 9, 234

\title{
Solution-phase phosphorus substitution for enhanced oxygen evolution reaction in $\mathrm{Cu}_{2} \mathrm{WS}_{4} \dagger$
}

\begin{abstract}
Travis G. Novak, ${ }^{a}$ Om Prakash, ${ }^{\mathrm{b}}$ Anand P. Tiwari ${ }^{\star a}$ and Seokwoo Jeon (D) *a
Transition metal phosphides are among the most promising materials for achieving efficient electrocatalytic performance without the use of rare or expensive noble metals. However, previous research into phosphides for the hydrogen evolution reaction (HER) or oxygen evolution reaction (OER) has focused on high-temperature vapor-phase processes, which are not practical for large-scale applications. Here, we introduce a simple, one-step solution-phase method of phosphide synthesis by modifying $\mathrm{Cu}_{2} \mathrm{WS}_{4}$ using triphenylphosphine (TPP), which serves to substitute $\mathrm{S}$ with $\mathrm{P}$ and transform the normally inactive basal plane of $\mathrm{Cu}_{2} \mathrm{WS}_{4}$ into a defect-rich, activated basal plane. The OER activity was significantly enhanced by phosphorus substitution, with the resulting Tafel slope of the sample with $\sim 8$ at\% phosphorus reaching $194 \mathrm{mV} \mathrm{dec}^{-1}$, a result close to that of the best OER catalyst $\left(\mathrm{RuO}_{2}, 151 \mathrm{mV} \mathrm{dec}^{-1}\right)$. The sample possessed stable OER performance, showing no degradation in current density over $\sim 24$ hours (500 cycles), proving the robust and stable nature of the phosphorus substitution. These results open the possibility for further phosphide catalyst development using this low-cost, solution-phase method.
\end{abstract}

Received 9th November 2018

Accepted 16th December 2018

DOI: 10.1039/c8ra09261c

rsc.li/rsc-advances catalytically inactive. ${ }^{11,12}$ For this reason, much of the research into TMCs for OER or HER has focused on the formation of defects, edge sites, or localized lattice strain in an effort to increase the active sites. ${ }^{\mathbf{1 3 - 1 8}}$ In particular, heteroatom doping, such as substituting $\mathrm{S}$ with $\mathrm{Se}$, has proven to be an effective strategy to increase the catalytic activity. ${ }^{19-21}$

However, nearly all of current research on these phosphides involves a high-temperature, vapor-phase process, with the most common conditions seeming to be a temperature of over $300{ }^{\circ} \mathrm{C}$ with sodium hypophosphite or red phosphorus in a tube furnace. ${ }^{\mathbf{8} 22-26}$ A notable exception is a solution-phase method reported by McEnaney et $a .^{27}$ to produce tungsten phosphide with trioctylphosphine, but the resulting product was entirely amorphous. The need for both high temperatures and an additional synthesis step to create crystalline phosphides significantly undermines the claims of low-cost and scalability in these works, making the development of alternative routes for phosphide synthesis crucial.

In this work, we introduce a novel solution-phase method for $\mathrm{P}$ substitution by using triphenylphosphine (TPP) in the $\mathrm{Cu}_{2} \mathrm{WS}_{4}$ system. Unlike the aforementioned works, this method achieves stable phosphide synthesis through a one-step, lowtemperature, solution-phase process. Through this method, the normally inactive basal plane of $\mathrm{Cu}_{2} \mathrm{WS}_{4}$ was transformed into a defect-rich, highly-active structure, resulting in a dramatic improvement in OER properties. The best composition $\left(\mathrm{Cu}_{2} \mathrm{WS}_{3.4} \mathrm{P}_{0.6}\right)$ shows a Tafel slope of $194 \mathrm{mV} \mathrm{dec}{ }^{-1}$, close to the value of $\mathrm{RuO}_{2}\left(151 \mathrm{mV} \mathrm{dec}{ }^{-1}\right)$. The result comes from the decreased adsorption energy of $-\mathrm{OH}$ on $\mathrm{Cu}_{2} \mathrm{WS}_{4}$, which was
${ }^{a}$ Department of Materials Science and Engineering, KAIST Institute for the Nanocentury, Advanced Battery Center, KAIST, Daejeon 305-701, Republic of Korea. E-mail:anand@kaist.ac.kr; jeon39@kaist.ac.kr

${ }^{b}$ Department of Inorganic and Physical Chemistry, Indian Institute of Sciences, Bengaluru 560012, India

$\dagger$ Electronic supplementary information (ESI) available. See DOI: 10.1039/c8ra09261c 
further analyzed with DFT simulations. These results show the potential of this novel solution-phase phosphorus substitution method for use in OER electrocatalysts.

\section{Results and discussion}

Fig. 1a illustrates the crystal structure of $\mathrm{Cu}_{2} \mathrm{WS}_{4}$ and $\mathrm{Cu}_{2} \mathrm{WS}_{4}$ with $\mathrm{P}$ substitution. $\mathrm{Cu}_{2} \mathrm{WS}_{4}$ reference samples were synthesized through a previously reported method. ${ }^{28,29}$ Phosphorus substitution was achieved by adding TPP to the mixture in amounts corresponding to $0.1,0.15$, and 0.20 molar ratios relative to the other precursors, which were designated as $\mathrm{Cu}_{2} \mathrm{WS}_{3.6} \mathrm{P}_{0.4}, \mathrm{Cu}_{2} \mathrm{WS}_{3.4} \mathrm{P}_{0.6}, \mathrm{Cu}_{2} \mathrm{WS}_{3.2} \mathrm{P}_{0.8}$, respectively. The XRD results in Fig. 1b show evidence of successful defect formation through $\mathrm{P}$ substitution. The major peaks correspond to $\mathrm{Cu}_{2} \mathrm{WS}_{4}$ (JCPDS 81-1159), but at higher concentrations the P substitution appears to add higher lattice strains, as evidenced by the inset showing the significant full-width half max (FWHM) increase. Similar XRD trends have been shown to indicate lattice strain ${ }^{16}$ and/or defect formation ${ }^{30}$ in previous reports of TMC catalysts. We note that no additional peaks were observed after P-doping, indicating that $\mathrm{P}$ substitutes into the $\mathrm{Cu}_{2} \mathrm{WS}_{4}$ lattice or forms defect sites rather than forming secondary crystalline phases.

XPS analysis (Fig. 1c) confirms the presence of phosphorus, reaching a maximum of $\sim 11$ at $\%$ in the $\mathrm{Cu}_{2} \mathrm{WS}_{3.2} \mathrm{P}_{0.8}$ sample. A significant shift of the $\mathrm{W} 4 \mathrm{f}$ peaks is also observed, an expected result due to the electronegativity difference between $\mathrm{S}$ and $\mathrm{P}$. Interestingly, the $\mathrm{Cu}$ peaks are not shifted, while the $\mathrm{S}$ peaks experience a much smaller and less progressive shift, as seen in Fig. S1. $\dagger$ Raman spectroscopy (Fig. 1d) also confirms the changes in the chemical state after P substitution. The standard $\mathrm{A}_{1}, \mathrm{~B}_{2}$, and $\mathrm{E}$ modes are present in all samples, which are characteristic of $\mathrm{Cu}_{2} \mathrm{WS}_{4}$, but the intensity decreases with increasing $\mathrm{P}$ concentration. Meanwhile, $\alpha$ and $\beta$ modes appear in samples with $\mathrm{P}$ substitution, and increase in prominence with increasing $\mathrm{P}$ concentration. The $\mathrm{A}_{1}, \mathrm{~B}_{2}$, and $\mathrm{E}$ modes are characteristic of $\mathrm{S}$ vibrations in $\mathrm{TMCs}^{31,32}$ and often broaden and decrease in intensity with increasing defect formation. ${ }^{30,33}$ Therefore, this is strong evidence for both P substitution in the lattice as well as increased defects in P-substituted sample.

The effect of P substitution was also seen in the morphology of the samples. The SEM images indicate only minor changes in the particle shape and size. The pristine sample (Fig. 2a, inset) appears monodisperse and with a small $(<50 \mathrm{~nm}$ diameter) size, while P-substituted samples appear to have slightly larger average particle sizes, and the $\mathrm{Cu}_{2} \mathrm{WS}_{3.2} \mathrm{P}_{0.8}$ develops a broader size distribution. However, the changes in crystallinity, as observed by HRTEM, are much more pronounced. Both the pristine $\mathrm{Cu}_{2} \mathrm{WS}_{4}$ and the $\mathrm{Cu}_{2} \mathrm{WS}_{3.6} \mathrm{P}_{0.4}$ samples appear fully crystalline, with no significant defects or amorphous regions. The $\mathrm{Cu}_{2} \mathrm{WS}_{3.4} \mathrm{P}_{0.6}$ in Fig. 2c sample appears to be slightly less
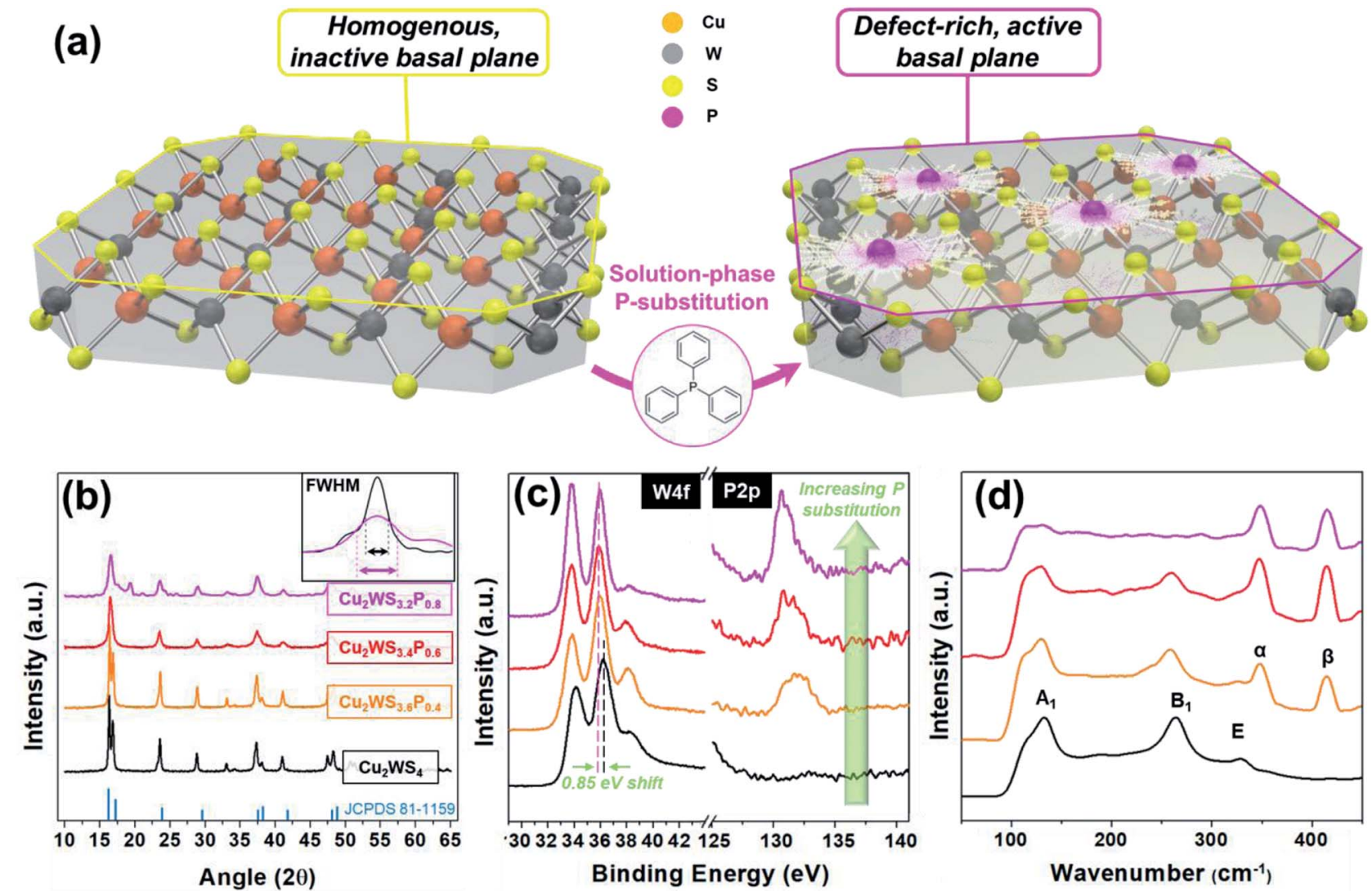

Fig. 1 Illustration of phosphorus substitution and basal plane activation using TPP (a). (b) XRD showing increased lattice strain and decreased crystallinity with increasing phosphorus substitution. (c) XPS showing a shift of the W $4 \mathrm{f}$ peaks and increase of P $2 p$ peaks. (d) Raman spectra with vibrational modes labeled. 

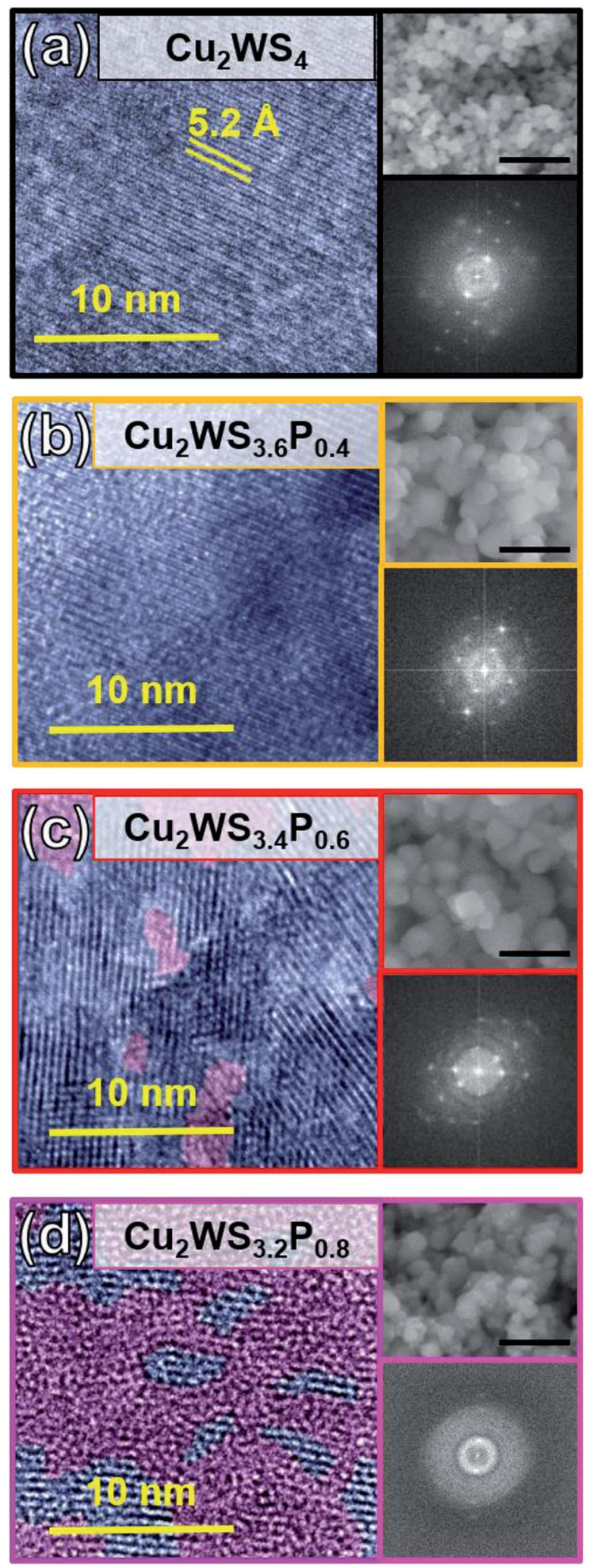

Fig. 2 False-color TEM images showing decreased crystallinity with increasing P-substitution (left). SEM images (scale bar $=500 \mathrm{~nm}$ ) and FFT patterns (right) also show the changes in sample crystallinity and morphology. crystalline, as indicated by the FFT pattern and false-color TEM image, where crystalline regions are colored light blue and amorphous regions are colored light pink. The $\mathrm{Cu}_{2} \mathrm{WS}_{3.2} \mathrm{P}_{0.8}$ sample (Fig. 2d) appears even less crystalline, with large amorphous regions observed and only very faint points appearing in the FFT pattern. The full set of SEM and TEM images are presented in Fig. S2. $\dagger$ A uniform distribution of $\mathrm{P}$ was also confirmed by Energy Dispersive X-ray Spectroscopy (EDS), as shown in Fig. S3.† Overall, these data agree well with the previously discussed Raman and XRD data, with both indicating that significant lattice strain and defect formation takes place after $\mathrm{P}$ substitution.

The oxygen evolution reaction (OER) performances of assynthesized pristine and P-substituted $\mathrm{Cu}_{2} \mathrm{WS}_{4}$ electrocatalysts were measured by dropping the catalyst slurry onto a rotating disk electrode (RDE) with a mass loading of $0.1 \mathrm{mg} \mathrm{cm}^{-2}$ in the $\mathrm{O}_{2}$-saturated $0.1 \mathrm{M} \mathrm{KOH}$ at the rotation of $1600 \mathrm{rpm}$. As seen in the linear sweep voltammetry (LSV) curves in Fig. 3a, the catalytic activity of the samples significantly improves after $\mathrm{P}$ substitution. The pristine $\mathrm{Cu}_{2} \mathrm{WS}_{4}$ sample is almost completely inactive for OER, which is typical for TMCs with no basal plane modification or edge structuring. ${ }^{29,34-37}$ After P substitution, the material is transformed into a highly active catalyst, with the $\mathrm{Cu}_{2} \mathrm{WS}_{3.4} \mathrm{P}_{0.6}$ sample showing the best performance (onset potential $1.59 \mathrm{~V} v s$. RHE at $10 \mathrm{~mA} \mathrm{~cm}{ }^{-2}$ ). Furthermore, to investigate the OER kinetics of the as-synthesized samples, Tafel plots (Fig. 3b) are fitted according to the polarization curves. As seen in the comparison of Tafel slopes, the value for $\mathrm{Cu}_{2} \mathrm{WS}_{3.4} \mathrm{P}_{0.6}\left(194 \mathrm{mV} \mathrm{dec}{ }^{-1}\right)$ is close to that of the benchmark $\mathrm{RuO}_{2}$ catalyst ( $\left.151 \mathrm{mV} \mathrm{dec}{ }^{-1}\right)$ tested under the same conditions. Although the phosphorus content is relatively low compared to the other constituent elements $\left(\sim 8\right.$ at $\% \mathrm{P}$ for $\left.\mathrm{Cu}_{2} \mathrm{WS}_{3.4} \mathrm{P}_{0.6}\right)$, we note that many other studies have confirmed that light doping $(<10$ at $\%)$ can produce dramatic improvements in electrocatalytic activity. ${ }^{35,38,39}$

However, the catalytic activity decreases with further $\mathrm{P}$ substitution, with the $\mathrm{Cu}_{2} \mathrm{WS}_{3.2} \mathrm{P}_{0.8}$ sample showing an onset potential of $1.67 \mathrm{~V} v$ s. RHE at $10 \mathrm{~mA} \mathrm{~cm}{ }^{-2}$ with a Tafel slope of $341 \mathrm{mV} \mathrm{dec}^{-1}$. Although a certain degree of defect formation is beneficial for catalytic activity, excessive defects can hinder performance by reducing electrical conductivity. ${ }^{40,41}$ Because $\mathrm{Cu}_{2} \mathrm{WS}_{3.2} \mathrm{P}_{0.8}$ was shown to have many amorphous regions and a heavily strained lattice in the previously discussed XRD and TEM data, we suspect that the electrical conductivity is negatively impacted as a result. However, the catalytic activity of $\mathrm{Cu}_{2} \mathrm{WS}_{3.6} \mathrm{P}_{0.4}$ (onset potential $1.70 \mathrm{~V} v$ s. RHE at $10 \mathrm{~mA} \mathrm{~cm}{ }^{-2}$ with Tafel slope $272 \mathrm{mV} \mathrm{dec}^{-1}$ ) sample reveals that $\sim 6$ at $\% \mathrm{P}$ is not enough to utilize the basal planes of $\mathrm{Cu}_{2} \mathrm{WS}_{4}$ for OER activity.

To further analyze the results, the double-layer capacitances $\left(C_{\mathrm{dl}}\right)$ are derived from the cyclic voltammetry to evaluate the electrochemical surface area (ECSA) of as-synthesized samples and is shown in Fig. 3c. Here, the $\mathrm{Cu}_{2} \mathrm{WS}_{3.4} \mathrm{P}_{0.6}$ appears to have superior properties, with the highest $C_{\mathrm{dl}}\left(3.1 \mathrm{mF} \mathrm{cm}^{-2}\right)$ confirming the increased number of active sites after Psubstitution. Impedance spectroscopy was also performed to gain insights into the charge transfer resistance of the samples, as seen in Fig. 3d. All samples show a characteristic 

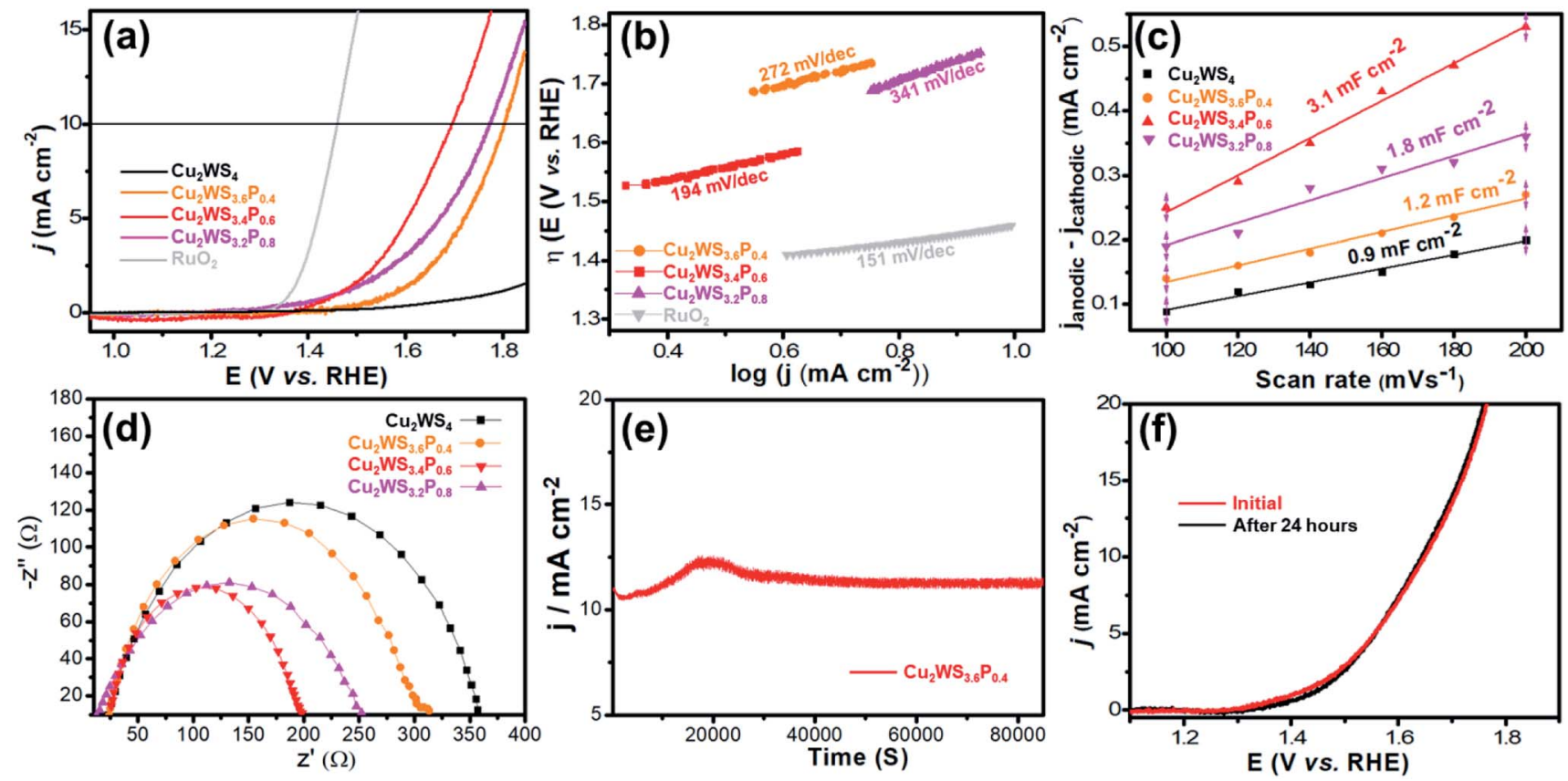

Fig. 3 Electrochemical properties of $\mathrm{Cu}_{2} \mathrm{WS}_{4}$ and P-substituted samples: LSV (a) and Tafel slopes (b) show a comparison of the P-substituted samples vs. the reference as well as vs. $\mathrm{RuO}_{2}$. ECSA (c) and impendence spectroscopy (d) indicate decreased charge transfer resistance and increased active sites with P-substitution. The stability test (e) as well as the comparison of LSV curves before and after the test (f) show the robust nature of the sample.

semicircular shape, and smallest area (lowest resistance $175 \Omega$ ) is seen in the $\mathrm{Cu}_{2} \mathrm{WS}_{3.4} \mathrm{P}_{0.6}$ sample.

Often, non-oxide OER compounds have poor stability in alkaline solutions. ${ }^{42}$ Here, we investigated stability of the best performing sample, $\mathrm{Cu}_{2} \mathrm{WS}_{3.4} \mathrm{P}_{0.6}$, over a period of $\sim 24$ hours. The sample showed a slight increase in current density in the initial stages of the test, followed by stabilization and no significant decay over the remainder of the measured time. As seen in the comparison of LSV curves in Fig. 3f, the catalytic activity is fully maintained after the stability test. XPS was also performed confirm that the phosphorus content remained after the stability test, as see in Fig. S5. $\dagger$ These data indicate that this method of P-substitution is stable and robust in the alkaline environment.

This improved performance after P-substitution can be attributed to increased active sites induced from defect and strain formation in the lattice. Previous research into TMCs for OER has shown that this disruption of the crystal structure can improve catalytic activity by reducing $\mathrm{OH}^{-}$adsorption energy. ${ }^{14,34}$ To support our experimental findings, density functional theory (DFT) calculations were employed to calculate the adsorption energy required for $\mathrm{OH}^{-}$on pristine $\mathrm{Cu}_{2} \mathrm{WS}_{4}$ and P-substituted $\mathrm{Cu}_{2} \mathrm{WS}_{4}$. To determine the adsorption energy of the adsorbent $\left(\mathrm{OH}^{-}\right)$on pristine $\mathrm{Cu}_{2} \mathrm{WS}_{4}$, and P-substituted $\mathrm{Cu}_{2} \mathrm{WS}_{4}\left(\mathrm{Cu}_{2} \mathrm{WS}_{3} \mathrm{P}\right.$ and $\left.\mathrm{Cu}_{2} \mathrm{WS}_{2} \mathrm{P}_{2}\right)$, first geometry optimizations were carried out for single molecule of $\mathrm{Cu}_{2} \mathrm{WS}_{4}, \mathrm{Cu}_{2} \mathrm{WS}_{3} \mathrm{P}$, and $\mathrm{Cu}_{2} \mathrm{WS}_{2} \mathrm{P}_{2}$ using the B3PW91 functional (shown in Fig. 4). Using long-range correlated (LC) van der Waals functional $\omega \mathrm{B} 97 \mathrm{XD}$, the calculated adsorption energy is $-6.75 \mathrm{eV}$, $-6.51 \mathrm{eV},-7.66 \mathrm{eV}$ for $\mathrm{Cu}_{2} \mathrm{WS}_{4}, \mathrm{Cu}_{2} \mathrm{WS}_{3} \mathrm{P}$, and $\mathrm{Cu}_{2} \mathrm{WS}_{2} \mathrm{P}_{2}$, respectively. Since the adsorption process of $\mathrm{OH}^{-}$on pristine

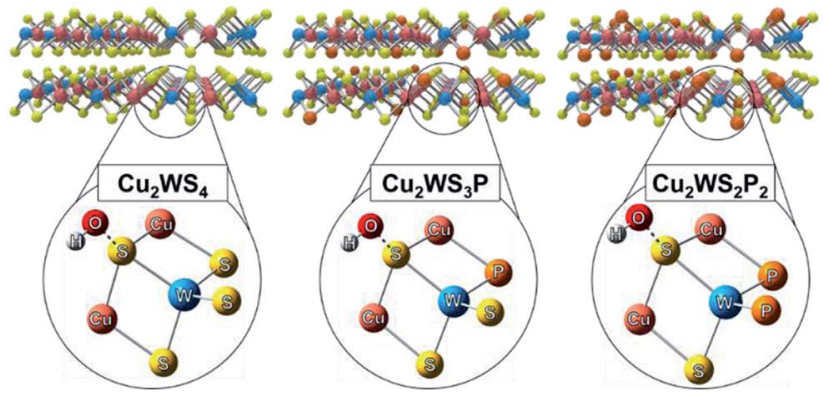

Fig. 4 Illustration of the layered samples (top) with the representative molecules used for DFT calculations and adsorbed $-\mathrm{OH}$ shown below.

$\mathrm{Cu}_{2} \mathrm{WS}_{4}$, and P-substituted molecules is physisorption caused by intermolecular van der Waals forces, it is expected the values calculated by functional $\omega \mathrm{B} 97 \mathrm{XD}$ is in nice agreement.

These DFT data agree well with the experimental results regarding OER activity. Because the -OH adsorption is lowered for the representative $\mathrm{Cu}_{2} \mathrm{WS}_{3} \mathrm{P}$ molecule, it is further evidence of the beneficial effects of P-substitution. However, the increased adsorption energy for the $\mathrm{Cu}_{2} \mathrm{WS}_{2} \mathrm{P}_{2}$ molecule could indicate an additional reason why the heavily P-substituted sample $\left(\mathrm{Cu}_{2} \mathrm{WS}_{3.4} \mathrm{P}_{0.6}\right)$ showed decreased catalytic activity compared to $\mathrm{Cu}_{2} \mathrm{WS}_{3.2} \mathrm{P}_{0.8}$. It is possible that while light Psubstitution decreases adsorption energy, adjacent are closely spaced $\mathrm{P}$ atoms interact to produce the opposite effect.

\section{Conclusions}

In summary, we have developed a low-temperature, solutionphase method to successfully substitute $\mathrm{S}$ with $\mathrm{P}$ in $\mathrm{Cu}_{2} \mathrm{WS}_{4}$. 
In contrast to the standard high-temperature, vapor-phase methods, this technique allows for the production of phosphides in a simple, one-step process. It was shown that $\mathrm{P}$ substitution creates a highly defective, active basal plane in the samples, which is beneficial for catalytic properties. As a result, the P-substituted samples showed significantly improved OER performance, a result which was attributed to the increased number of active sites and decreased charge transfer resistance compared to the reference sample. These results are of interest for further development of low-cost phosphides for electrochemical catalysts.

\section{Experimental procedures}

Pristine $\mathrm{Cu}_{2} \mathrm{WS}_{4}$ was synthesized using a solvothermal method..$^{28,29}$ In a typical reaction, $1.56 \mathrm{mmol}$ of $[\mathrm{Cu}(\mathrm{MeCN})] \mathrm{BF}_{4}$ is added to $20 \mathrm{ml}$ acetonitrile and $0.78 \mathrm{mmol}$ of $\left(\mathrm{NH}_{4}\right) \mathrm{WS}_{4}$ is added to $20 \mathrm{ml}$ dimethylformamide (DMF). The solutions were then mixed together in an $\mathrm{N}_{2}$ atmosphere and refluxed at $160{ }^{\circ} \mathrm{C}$ for 12 hours. The product was then collected using vacuum filtration over a PVDF membrane, rinsed with ethanol and deionized (DI) water, and dried in air at $65{ }^{\circ} \mathrm{C}$ overnight. For $\mathrm{P}$ substitution, triphenylphosphine (TPP) was added to the mixture prior to refluxing in molar ratios of $0.10,0.15$, and 0.20 .

$\mathrm{X}$-ray diffraction (XRD) patterns were obtained using $\mathrm{Cu} \mathrm{K} \alpha 1$ radiation (Rigaku, D/MAX-2500) with a scan rate of $2^{\circ} \mathrm{min}^{-1}$. Chemical analysis was performed using X-ray photoelectron spectroscopy (Thermo VG Scientific, K-alpha) and Raman spectroscopy using a $532 \mathrm{~nm}$ laser source (Bruker, Senterra). Scanning electron microscopy (SEM) images were obtained using a Hitachi SU5000, and high-resolution transmission electron microscopy (HRTEM) was performed by drying the solutions over a carbon grid and imaging using an FEI Titan cubed G2.

Electrodes were fabricated by first sonicating $30 \mathrm{mg}$ of the active material with $8 \mathrm{ml}$ of DI water, $2 \mathrm{ml}$ ethanol, and $100 \mu \mathrm{l}$ Nafion ${ }^{\circledR} 117$ solution (5\%) for $1 \mathrm{~h}$. Then, $1 \mu \mathrm{l}$ of the prepared homogenous suspension was drop-cast onto a rotating glassy carbon electrode disc $(d=3 \mathrm{~mm})$. The samples were then dried at $60{ }^{\circ} \mathrm{C}$ overnight before use. Electrochemical analyses were performed using a VersaSTAT 3 electrochemical workstation with rotating disc electrode system (AMETEK, 616B). A three electrode system was used, where the working electrode is the active material/glassy carbon disc, the reference electrode is $\mathrm{Ag} /$ $\mathrm{AgCl}$ in $3 \mathrm{M} \mathrm{KCl}$, and the counter electrode is a Pt mesh in $0.1 \mathrm{M}$ $\mathrm{KOH}(\mathrm{pH}=11)$. All of the potentials were calibrated to a RHE, $E_{\mathrm{RHE}}=E_{\mathrm{Ag} / \mathrm{AgCl}}+0.196+0.0591 \mathrm{pH} \mathrm{V}$.

The Gaussian 09 and GaussView 5.0 package was used for density functional theory (DFT) based calculation. To determine the adsorption energy of the adsorbent $\left(\mathrm{OH}^{-}\right)$on pristine $\mathrm{Cu}_{2} \mathrm{WS}_{4}$, and P-doped $\mathrm{Cu}_{2} \mathrm{WS}_{4}\left(\mathrm{Cu}_{2} \mathrm{WS}_{3} \mathrm{P}, \mathrm{Cu}_{2} \mathrm{WS}_{2} \mathrm{P}_{2}\right.$, and $\mathrm{Cu}_{2} \mathrm{WS}_{1} \mathrm{P}_{3}$ ), first geometry optimizations were carried out for single molecule of $\mathrm{Cu}_{2} \mathrm{WS}_{4}, \mathrm{Cu}_{2} \mathrm{WS}_{3} \mathrm{P}$, and $\mathrm{Cu}_{2} \mathrm{WS}_{2} \mathrm{P}_{2}$, using the B3PW91 functional. The 6-311G(d,p) basis set was used for S, P, $\mathrm{O}, \mathrm{H}$ atoms and LANL2DZ basis set was used for metals $\mathrm{Cu}, \mathrm{W}$. After geometry optimization, the adsorption energy was calculated using functionals B3PW91 and $\omega$ B97XD with counterpoise corrections to correct for basis set superposition error (BSSE). The functionals B3PW91 and $\omega$ B97XD are local density functional and long-range correlated (LC) van der Waals functionals, respectively.

\section{Conflicts of interest}

There are no conflicts to declare.

\section{Acknowledgements}

This work was supported by the National Research Foundation of Korea (NRF) under grant no. NRF-2017R1D1A1B03032791, and National Research Foundation of Korea (NRF) funded by the Ministry of Science and ICT (2017M3D1A1039558).

\section{References}

1 N.-T. Suen, S.-F. Hung, Q. Quan, N. Zhang, Y.-J. Xu and H. M. Chen, Chem. Soc. Rev., 2017, 46, 337-365.

2 M. Tahir, L. Pan, F. Idress, X. Zhang, L. Wang, J.-J. Zou and Z. L. Wang, Nano Energy, 2017, 37, 136-157.

3 Z. Wu, X. Li, W. Liu, Y. Zhong, Q. Gan, X. Li and H. Wang, ACS Catal., 2017, 7, 4026-4032.

4 W. Liu, E. Hu, H. Jiang, Y. Xiang, Z. Weng, M. Li, Q. Fan, X. Yu, E. I. Altman and H. Wang, Nat. Commun., 2016, 7, 10771.

5 L. Zeng, K. Sun, X. Wang, Y. Liu, Y. Pan, Z. Liu, D. Cao, Y. Song, S. Liu and C. Liu, Nano Energy, 2018, 51, 26-36.

6 H. Yan, C. Tian, L. Wang, A. Wu, M. Meng, L. Zhao and H. Fu, Angew. Chem., Int. Ed., 2015, 54, 6325-6329.

7 X.-D. Wang, Y.-F. Xu, H.-S. Rao, W.-J. Xu, H.-Y. Chen, W.-X. Zhang and C.-Y. S. D.-B. Kuang, Energy Environ. Sci., 2016, 9, 1468-1475.

8 Z. Pu, X. Ya, I. S. Amiinu, Z. Tu, X. Liu, W. Li and S. Mu, J. Mater. Chem. A, 2016, 4, 15327-15332.

9 J. Kibsgaard and T. F. Jaramillo, Angew. Chem., Int. Ed., 2014, 53, 14433-14437.

10 A. Wu, C. Tian, H. Yan, Y. Jiao, Q. Yan, G. Yang and H. Fu, Nanoscale, 2016, 8, 11052-11059.

11 J. Wu, M. Liu, K. Chatterjee, K. P. Hackenberg, J. Shen, X. Zou, Y. Yan, J. Gu, Y. Yang, J. Lou and P. M. Ajayan, Adv. Mater. Interfaces, 2016, 3, 1500669.

12 T. F. Jaramillo, K. P. Jørgensen, J. Bonde, J. H. Nielsen, S. Horch and I. Chorkendorff, Science, 2007, 317, 100-102.

13 M. A. Lukowski, A. S. Daniel, C. R. English, F. Meng, A. Forticaux, R. J. Hamers and S. Jin, Energy Environ. Sci., 2014, 7, 2608-2613.

14 Y. Xue, Z. Ren, Y. Xie, S. Du, J. Wu, H. Meng and H. Fu, Nanoscale, 2017, 9, 16256-16263.

15 B. Mohanty, M. Ghorbani-Asl, S. Kretschmer, A. Ghosh, P. Guha, S. K. Panda, B. Jena, A. V. Krasheninnikov and B. K. Jena, ACS Catal., 2018, 8, 1683-1689.

16 A. P. Tiwari, A. Azam, T. G. Novak, O. Prakash and S. Jeon, J. Mater. Chem. A, 2018, 6, 7786-7793.

17 G. Ye, Y. Gong, J. Lin, B. Li, Y. He, S. T. Pantelides, W. Zhou, R. Vajtai and P. M. Ajayan, Nano Lett., 2016, 16, 1097-1103. 
18 K. Yan and Y. Lu, Small, 2016, 12, 2975-2981.

19 K. Xu, F. Wang, Z. Wang, X. Zhan, Q. Wang, Z. Cheng, M. Safdar and J. He, ACS Nano, 2014, 8, 8468-8476.

20 X. Zhou, J. Prikryl, M. Krbal, J. M. Macak and P. Schmuki, Electrochem. Commun., 2017, 82, 112-116.

21 Q. Gong, L. Cheng, C. Liu, M. Zhang, Q. Feng, H. Ye, M. Zeng, L. Xie, Z. Liu and Y. Li, ACS Catal., 2015, 5, 22132219.

22 C. Guan, W. Xiao, H. Wu, X. Liu, W. Zang, H. Zhang, J. Ding, Y. P. Feng, S. J. Pennycook and J. Wang, Nano Energy, 2018, 48, 73-80.

23 L. Yan, L. Cao, P. Dau, X. Gu, D. Liu, L. Li, Y. Wang and X. Zhao, Adv. Funct. Mater., 2017, 27, 1703455.

24 J. Song, B. Z. X. C. Zhu, S. Fu, M. H. Engelhard, R. Ye, D. Du, S. P. Beckman and Y. Lin, Adv. Energy Mater., 2017, 7, 1601555. 25 J. Xu, J. P. S. Sousa, N. E. Mordvinoa, J. D. Costa, D. Y. Petrovykh, K. Kovnir, O. I. Lebedev and Y. V. Kolen'ko, ACS Catal., 2018, 8, 2595-2600.

26 K. Liu, C. Zhang, Y. Sun, G. Zhang, X. Shen, F. Zou, H. Zhang, Z. Wu, E. C. Wegener, C. J. Taubert, J. T. Miller, Z. Peng and Y. Zhu, ACS Nano, 2018, 12, 158-167.

27 J. M. McEnaney, J. Chance Crompton, J. F. Callejas, E. J. Popczun, C. G. Read, N. S. Lewis and R. E. Schaak, Chem. Commun., 2014, 50, 11026-11028.

28 A. P. Tiwari, D. Kim, Y. Kim, O. Prakash and H. Lee, Nano Energy, 2016, 28, 366-372.

29 Y. Kim, A. P. Tiwari, O. Prakash and H. Lee, ChemPlusChem, 2017, 82, 785-791.

30 T. Naresh Kumar, N. Chandrasekaran and K. Lakshminarasimha Phani, Chem. Commun., 2015, 51, 5052-5055.
31 H. Chen, K. Zhang, W. Chen, I. Ali, P. Wu, D. Liu and L. Song, AIP Adv., 2015, 5, 037141.

32 A. Azam, J. Kim, J. Park, T. G. Novak, A. P. Tiwari, S. H. Song, B. Kim and S. Jeon, Nano Lett., 2018, 18, 5646-5651.

33 S. Wei, L. Miao-Ling, T. Qing-Hai, Q. Xiao-Fen, Z. Jun and T. Ping-Heng, 2D Mater., 2016, 3, 025016.

34 J. Zhang, T. Wang, D. Pohl, B. Rellinghaus, R. Dong, S. Liu, X. Zhuang and X. Feng, Angew. Chem., 2016, 128, 6814-6819.

35 Q. Xiong, Y. Wang, P.-F. Liu, L.-R. Zheng, G. Wang, H.-G. Yang, P.-K. Wong, H. Zhang and H. Zhao, Adv. Mater., 2018, 30, 1801450.

36 Y. Wu, F. Li, W. Chen, Q. Xiang, Y. Ma, H. Zhu, P. Tao, C. Song, W. Shang, T. Deng and J. Wu, Adv. Mater., 2018, 30, 1803151.

37 A. P. Tiwari, D. Kim, Y. Kim and H. Lee, Adv. Energy Mater., 2017, 7, 1602217.

38 Z. Luo, Y. Ouyang, H. Zhang, M. Xiao, J. Ge, Z. Jiang, J. Wang, D. Tang, X. Cao, C. Liu and W. Xing, Nat. Commun., 2018, 9, 2120.

39 J. Xie, J. Zhang, S. Li, F. Grote, X. Zhang, H. Zhang, R. Wang, Y. Lei, B. Pan and Y. Xie, J. Am. Chem. Soc., 2013, 135, 1788117888.

40 X. Zhang, F. Meng, S. Mao, Q. Ding, M. J. Shearer, M. S. Faber, J. Chen, R. J. Hamers and S. Jin, Energy Environ. Sci., 2015, 8, 862-868.

41 Y. Yoon, A. P. Tiwari, M. Lee, M. Choi, W. Song, J. Im, T. Zyung, H.-k. Jung, S. S. Lee, S. Jeon and K.-S. An, J. Mater. Chem. A, 2018, 6, 20869-20877.

42 X. Xu, F. Song and X. Hu, Nat. Commun., 2016, 7, 12324. 